\title{
An Open and Adaptable Platform for the elderly people and persons with disability to access the Information Society. The Naviga Project
}

\author{
Diego Gachet Páez, Manuel de Buenaga \\ Escuela Superior Politécnica \\ Universidad Europea de Madrid \\ Villaviciosa de Odón, Madrid, Spain \\ \{gachet,buenaga\}@uem.es
}

\begin{abstract}
NAVIGA is an European project whose main goal is to design and develop a technological platform allowing elderly people and persons with disability to access the Internet and the Information Society through an innovative and adaptable navigator. NAVIGA also allows the creation of services targeted to social networks, mind training and personalized health care.
\end{abstract} living.

Keywords-component; elderly, wellbeing, ambient assisted

\section{INTRODUCTION}

Today, developed countries have great difficulties for effective health services and quality of care in a context marked by the population's ageing. This trend has dramatic effects on both public and private health systems as well on emergency medical services, mainly due to increase of costs and also growth of demand for more and better benefits by users as well as increasing people mobility.

This demographic change will lead to significant and interrelated changes in the health care sector and technologies promoting the independence for older persons. As representative data, the 20 to 64 years old make up for approximately $64 \%$ of the European population at present and the over 65 cover $17 \%$, so there are 4 working employees to one pensioner approximately. On the other hand it is estimated that the 20 to 64 years old will decrease to $55 \%$ and the over 65 will increase to $28 \%$ for the year 2050 , being the prior proportion 1 to 2 instead 1 to 4 .

The population in developed countries lives more due to the best live and health conditions, for example in North America only $4.5 \%$ of population over 65 years old are living in nursing homes, a percentage that has decreased in recent years, the population of elderly people is constantly prepared for better ageing due to a reduction in disability, as a result the elder people become more active in their daily lives. Despite the improvement in conditions for carrying out ageing and continue living actively, there are obvious changes that occur in the behaviours and skills in the latter part of life, these changes may include decreases in social relations and physical abilities, loss of memory and comprehensive and cognitive functions.

Permission to make digital or hard copies of all or part of this work for personal or classroom use is granted without fee provided that copies are not made or distributed for profit or commercial advantage and that copies bear this notice and the full citation on the first page. To copy otherwise, to republish, to post on
servers or to redistribute to lists, requires prior specific permission and/or a fee. PERVASIVEHEALTH 2010, March 22-25, Munchen, Germany Copyright (C) 2010 ICST 978-963-9799-89-9

DOI 10.4108/ICST.PERVASIVEHEALTH2010.8882

\author{
M. Villalba, Pedro Lara \\ Escuela Superior Politécnica \\ Universidad Europea de Madrid \\ Villaviciosa de Odón, Madrid, Spain \\ \{maite.villalba,pedro.lara\}@uem.es
}

The actual trend is improving the quality of life of elder persons, not only extend its duration, the gerotechnology [1], is a very active application to improve the life of adult persons, considered a special users whose particular skills and needs on cognitive social and health levels must be taken into account during the process of designing any technological solution focussed to this group. Also, we must consider elderly and disabled people have serious difficulties to access the information society and the benefits it provides in areas such as eHealth or leisure. Older people often aren't comfortable driving a computer and the technological devices seems to be complicated for them. This problem may worsen due decreasing of cognitive, visual, hearing or motor capacity.

The Naviga project (2009-2012) is an European effort funded under Eurostar [2] program and whose main objective is to provide these collective simple methods to overcome these barriers and enjoy greater personal autonomy and a better quality of life. To do this, the Naviga project will provide an integrated platform that facilitates an Internet access for all through their computer or TV, and also allowing employ alternative keyboard for navigation devices. In addition, the Naviga platform will have services that facilitate the incorporation of elders and people with diverse functional capacity to the Information Society using Information and Communication Technology to maintain their minds agile and involve them actively in his community of relatives and friends, while allowing them to control their health. Moreover, as an open system, the Naviga platform allows connecting external devices, so users can connect various accessible devices as controls, buttons, or specific sensors. Similarly the Naviga platform allows the incorporation of new services as well integrating the existing ones and provides a common interface for interaction with users.

\section{Problems to Be Addressed at Naviga ProJect}

The NAVIGA project intends to solve different problems that can be viewed from different points of view:

\section{A. Target market: at this point there are the following markets}


Health: The NAVIGA project will allow health centers for the creation of various services. Even part of the effort of the project would be devoted to the construction of serviceoriented world of health. This sector demands a technological aid especially in the control patients, particularly older people. In addition, this group tends to be far from the technologies that currently are being launched with what would be appropriate to bring this technology to such users. Also, it would be possible to develop services to help those who temporarily are with reduced mobility to be able to access a simple and useful way to the hospital services.

Educational: The project will make available to groups working with people with disabilities, tools with which to develop services tailored to people with these disabilities. Thus, the entities that work with disabled people can build educational services tailored to these users.

Public administration. For public entities, it is important to incorporate all people to new forms of participation that brings the Information Society. The public sector is one that has the greatest responsibility when it comes to breaking the digital divide, both to the elderly and disabled. The NAVIGA project can be a key point for the access to electronic administration of these groups.

\section{B. Objective user: mainly users of the services provided by the NAVIGA project are:}

People with disabilities. Users with varying degrees of disabilities have special needs when it comes to using a computer system. They may need input data interfaces specially designed for them, for example the pushers. Furthermore, these users also have special needs in the system usability, it is necessary to implement the method to perform complex actions through very simple mechanisms. These mechanisms may be sweeping the active elements of a fullscreen, so that a person with reduced mobility can access all of these elements through a switch.

Seniors, this group of users, can combine two different aspects. The first one is very similar to that described above for users with reduced mobility. For example, a person with Parkinson's disease has reduced its ability to use a computer system. Through the mechanisms that implement the project for people with reduced mobility, these patients may have access to the implemented services. The second aspect is through the breakdown of the digital gap. By having an extremely simple interface and fully adapted to their needs, these users will have less than a rejection by a system of the complexity of current computer systems.

Another important consideration for organizations is that Web accessibility is required by laws and policies in some cases. Examples of countries with legislation relevant to web accessibility include:
- Germany: Act on Equal Opportunities for Disabled Persons of 27 April 2002.

- Ireland: The Disability Act (2005). The Equal Status Act (200) and the Employment Equality Act (1998).

- Italy: Provisions to Support the Access to Information Technologies for the Disabled (January 2004).

- Portugal: Resolution of the Council of Ministers Concerning Accessibility of Public Administration Web Sites for Citizens with Special Needs (1999).

- Spain: LAW 34/2002, of 11 of July, services of the information society and electronic commerce).

- UK: The Disability Discrimination Act (1995), the Special Educational Needs and Disability Act (2001), and the Disability Discrimination Act (1995).

\section{RESEARCH METHOD}

The research and development part of the NAVIGA project will be based on the Reference Model of Open Distributed Processing (RM-ODP) [3]. The RM-ODP framework was a joint effort by the international standards bodies ISO and ITUT to develop a coordinating framework for the standardization of open distributed processing. The model describes an architecture within which support of distribution, interworking, interoperability and portability can be integrated. With the aid of RM-ODP it will be easier to organize the pieces that compose NAVIGA into a coherent whole.

RM-ODP defines five viewpoints (providing concepts, structures and rules) from which to abstract ODP systems.

The main advantage of RM-ODP is that specifying NAVIGA using these viewpoints allows an otherwise large and complex project to be separated into manageable pieces, each focused on the issues relevant to different members of the development team.

The viewpoints defined by RM-ODP are:

- Enterprise: purpose, scope and policies.

- Information: information and information processing.

- Computational: functional decomposition.

- Engineering: infrastructure required to support distribution.

- Technology: choices of technology for implementation.

Based on the RMODP viewpoints, the work to be performed in NAVIGA project has been organized into several phases and tasks within the phases.

From the point of view of service provisioning NAVIGA will be based on a Service Oriented Architecture (SOA). SOA is an architectural style that guides all aspects of creating and using business processes, packaged as services, throughout their lifecycle, as well as defining and provisioning the IT infrastructure that allows different applications to exchange data and participate in business processes loosely coupled from the operating systems and programming languages underlying those applications. 
SOA represents a model in which functionality is decomposed into distinct units (services), which can be distributed over a network and can be combined together and reused to create business applications.

These services communicate with each other by passing data from one service to another, or by coordinating an activity between two or more services. The concepts of service-oriented architecture are often seen as built upon, and the evolution of, the older concepts of distributed computing and modular programming.

The NAVIGA middleware will be composed of three layers: Presentation Layer, Business Layer and Integration Layer. Each layer builds new services on top of the previous layer. Applications developed with the NAVIGA framework only need to deal with the Presentation Layer. Business and Integration Layers, can be extended to add new functionality to the NAVIGA framework.

The Integration Layer will provide an abstraction layer for the different models to integrate in the platform (databases, connectivity, and others). The integration layer will based on a set of "integration devices" specifically designed for each element to integrate into the platform.

Theses integration devices will be responsible to hide the characteristics of each element to integrate, and they will provide a unified and consistent view of services to the Business Layer.

The Business Layer will provide the implementation of all the business logic necessary for the development of novel collaborative applications for mobile devices. The Business Layer will provide a family of services to the Presentation Layer (accounting, billing, lobby services, and others). The Business Layer will provide a single entry point where a service dispatcher will provide the requested service to the presentation layer.

The Presentation Layer will be responsible for the interaction with end users, and it will focus on application polishness and appeal. The main goal of the Presentation Layer is to guarantee easy to use applications and esthetically appealing applications.

\section{NAVIGA MAIN COMPONENTS}

\section{A. Multi-functions platform}

The system will be used for specialized teleconsulting, for memory and nutritional reports, for tele-reeducation at home, for diagnostic tele-assistance or therapy, for tele-surveillance with detection and analysis of abnormal reactions.

\section{B. Adaptable device and communications interface}

One of the task of the Naviga project focuses on the development of a complete intelligent platform allowing data acquisition / reception / processing / communication: audio scene analysis and robust voice recognition, image and pattern recognition, people falling and alarm system could be integrated to this intelligent platform.

\section{Platform for the creation and deployment of services and applications}

A framework / platform / will be developed and to host new services and applications. The platform will be the kernel of NAVIGA project. The platform will run like a pseudo operating system that it will encapsulate the special operations for the objective user of the system. All the services that will develop on the project frame, will communicate with the user through the platform. The platform will provide the gadgets for the correct operation of all services, for example:

- The methods that user use for interact with the system, like sweep of the screen.

- The encapsulation of the access to the special hardware developed into NAVIGA project.

The main reason of this architecture is the maintenance and the scalability. If somebody wants to develop new solutions or services for the objective user of NAVIGA project, they could make it with the platform tools and the integration with developed services will be immediate.

\section{Web navigator}

In the case of web navigator the way most people $65+$ get internet information is via web browser, the problem therefore is to improve the interaction way between elderly people and browser via inputs elements as pulsers or voice commanded interfaces, and at the other hand adapting web pages providing information that senior needs [4]. In this sense NAVIGA introduce innovation at the design level of web browser applying the "Design for All" concept which consists of three strategies: (1) Products/services and applications should be usable by as many people as possible - regardless of age, ability or situation - without any modifications. (2) Products should be easily adaptable to different users. (3) Products should have standardized interfaces capable of being accessed by specialized users. It is a concept that emerged from "barrierfree" or "accessible design" and "assistive technology".

\section{E. Social networks}

NAVIGA will permit to create social networks. We have recently seen on Internet the appearance of the Web 2.0, the second generation of web based communities and services (wikis, folksonomies, blogs, mashups) [5] with the aim of facilitating the collaboration and sharing of contents between users.

\section{F. Healthcare services}

NAVIGA will ease the development of Healthcare services in a multi-functional integrated platform.

\section{G. Stimulation and entertainment systems}

Playing computer games for elderly is beneficial for them in several ways. Games can help lighten the spirit of a senior, and also help to keep their mind agile. The brain is a muscle and to stay sharp it needs regular exercise. During aging it's easy to observe the deterioration of some mind faculties, principally attention, the executive functions and memory. It should be pointed out that mathematical calculation continues 
to be an activity that suffers with the aging process. For elderly people feel satisfied in their daily lives is essential to maintain the cognitive health, and then are necessary exercises that keep attention, memory and calculation.

Although little is known about senior adults' perceived benefits of digital games, there is a small but growing body of research evidence in support of the notion that digital games can have a significant positive impact on the elder person's mental and physical health and wellbeing [6]. Some research [7] showed benefits of gaming practice for elderly people in several domains: stimulation of social interaction and participation; enhancement of perceptual-motor skills (eyehand coordination, dexterity, and fine motor abilities); improvement of performance speed (basic movements and reaction time); information processing, reading, comprehension, memory, self-image, etc. and transfer of the skills acquired in the games to other aspects of everyday routine like automobile driving.

The mental stimulation provided by computer games prevents or slows brain function deterioration in those with dementia and amongst elderly people in general. At the other hand, standard play in most computer games offer at least an indirect measure of memory use for seniors, however, to obtain a more direct measure of short term and working memory, it is possible to adapt for example the standard Concentration card game, users must remember the location of various cards they select (turn over to view the face of the card) and then match pairs [8]. Game difficulty is adapted based on number of cards and the cognitive difficulty of the matches. These range from simple shape and colour matches to cognitively more difficult matches, such as matching a digital clock time with the analogue picture equivalent.

In Naviga project, the value proposition includes enhanced memory, delayed cognitive decline (and physical), improved quality of life, reduced caregiver burdens and reduced cost of care to payers. These include computer-based cognitive stimulation products that rely on the plasticity property of memory [9]. There is preliminary evidence that these technologies may have positive impacts on memory in the short term. NAVIGA innovates incorporating embedded assessment capabilities.

\section{EXPECTED RESULTS}

The expected results of the project are:

- A hardware interface device set adaptable to the senior people and persons with disabilities and enabling the interface with the computer or television.

- A framework (tools and methods) for the creation and deployment of services and applications.

- The development of services including a web navigator allowing the access of elderly people and persons with disabilities to the Internet.

- Two technology demonstrators in the area of eHealth and Entertainment.
- An analysis of business opportunities and business requirements (identifying their key strengths and weakness) for the successful commercialization of project results.

Naviga project includes two case-study / scenarios to demonstrate the functionality of the developed framework. A concrete pilot application will be developed and evaluated in a Hospital targeting at the validation of a medical care service. Another scenario will be developed and evaluated in a specific Healthcare centre, targeting the access of elderly people and persons with disabilities to the Information Society through web specific navigator access, social networks and mind training. The scenarios will include the participation of real end-users to validate the technological developments.

The consortium is composed of 5 research-performing SMEs (investing min. $20 \%$ of annual turnover in R\&D), one University and two end users (one Hospital and a daily Healthcare centre located both in the Madrid region) will participate in the project.

\section{CONCLUSIONS}

The results of the Naviga Project will be ensuring from its early stages with the support of various end users allowing a correct project requirements stage, based on the real needs of the groups involved, and participating in the process of validation interfaces and services. End users with diverse functional capacity will test and validate project services us to know if them are useful. The Naviga project brings together six European entities, all experts in various areas of social and ICT sectors.

Twenty four months after the launch of the project, the consortium intends to start the initial exploitation of the NAVIGA project through its launch into the market. This will favor many actors throughout the whole value chain: end users / healthcare centre / developers:

\section{A. Elderly people and people with disabilities.}

The Web and Information and Communication Technology (ICT) are today an increasingly important resource in many aspects of life: education, employment, government, commerce and also health care, recreation and training (objectives of NAVIGA). It is essential that these technologies are accessible in order to provide equal access and equal opportunity to people with disabilities. An accessible Web will also help people with disabilities to participate more actively in the Society of the Information Society in general.

These improvements in the portal usability will be also very useful to another commonly technologically-marginalized collective: seniors. European countries had nine of the top ten highest median ages in national populations in 2005, and 32 per cent of the world population will be over 60 by 2050 , becoming this way another consumer target group that needs help dealing with the accessibility of Web pages. 


\section{B. Healthcare entities}

Of course, NAVIGA will provide a mean for Healthcare entities (Hospitals, Healthcare centre, etc) to better attend elderly people and people with disabilities through a set of well-defined applications and services.

While being able to attend a wider base of disabled and elderly people at any time (computers/televisions/hardware devices do not sleep), NAVIGA will also allow big savings in terms of both human resources and money for these Healthcare entities worldwide.

\section{Software houses (particularly SMEs)}

The Web offers the possibility of unprecedented access to information and interaction for many people with disabilities. That is, the accessibility barriers to print, audio, and visual media can be much more easily overcome through Web technologies. The solutions provided in this project for accessibility obstacles related to specific disabilities could be used as a reference guide for other software programmers and developers.

A better platform for developing eHealth applications and services will give Europe more possibilities to have a leading position in the world-wide market, since it will enhance the productivity of the European software industry in eHealth applications.

While it is true that a NAVIGA-type project in principle benefits the community world-wide, it is also true that the knowledge created by such projects tends to stay and be more fruitful in the places where it evolved. The mid and long-term benefits this will bring to the European software industry are enormous in terms of, e.g., self-supportability and independence from tools produced by non-European companies.

The infrastructure provided by NAVIGA will be reusable by other projects and will help at producing better software within the growing eHealthcare market. NAVIGA will help European software developers to increases their productivity, to enhance applications quality and to reduce service time-tomarket with a shorter test phase of most software intensive products.

NAVIGA will be a fundamental instrument to help other companies that develop applications and services oriented to eHealth. NAVIGA will bring new market opportunities to software companies and will provide a major competitive advantage to European players. This will highly benefit SMEs, which account for the majority of the European industrial sector.

\section{Web 2.0 concept and social networks}

NAVIGA is also market targeted to users for entertainment. NAVIGA responds to the growing demand around the web 2.0 concept: collaboration and sharing between end users. Within today's globalization phenomenon, NAVIGA will play a key role to increase and develop the web 2.0 concept.

\section{REFERENCES}

[1] Burdick, D.C., and Kwon, S. Gerotechnology: Research and Practice in Technology and Aging. New York: Springer Publishing Company.204

[2] Eurostar program web site. http://www eurostars-eureka.eu/ 2010

[3] RM-ODP web site. http:/Www.rm-odp.net/. 2010

[4] J. Clerk Maxwell, A Treatise on Electricity and Magnetism, 3rd ed., vol. 2. Oxford: Clarendon, 1892, pp.68-73.

[5] Gartner, "Gartner Reveals Five Social Software Predictions for 2010 and Beyond," 2010.: http //www.gartner.com/it/page.jsp?id=1293114.

[6] Griffiths, M. The therapeutic value of video games. In Raessens, J \& Goldstein, J. (Eds.) Handbook of Computer Games Studies (pp. 161171). Cambridge, MA: The MIT Press.. 2005

[7] Whitcomb, G. Robert. Computer games for the elderly. number 4. pp 373- 393. In CQL '90: Proceedings of the conference on Computers and the quality of life (1990), pp. 112-115. appears in (pp. 19-29). Hershey, PA: Information Science Reference. 1990

[8] Jimison, H.B., Pavel, M., McKanna, J., Pavel, J. Unobtrusive Monitoring of Computer Interactions to Detect Cognitive Status in Elders, IEEE Transactions on Information Technology in Biomedicine, Vol. 8, No. 3, pp. 248-252. 2004

[9] Czaja, S.J., \& Lee, C.C. "Information technology and older adults". In J.A. Jacko \& A.Sears (Eds.), The human-computer interaction handbook (2nd ed.). New York. Erlbaum. 2007. 